\title{
Contrast induced nephropathy in elective versus urgent non-diabetic patients
}

\section{Zvonimir Ostojić*, Zoran Miovski, Marija Brestovac, Joško Bulum}

University of Zagreb School of Medicine, University Hospital Centre Zagreb, Zagreb, Croatia
RECEIVED:

September 24, 2017

ACCEPTED:

September 26, 2017

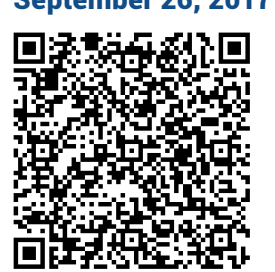

KEYWORDS: contrast induced nephropathy, cardiovascular interventions, percutaneous coronary intervention/complications.

CITATION: Cardiol Croat. 2017;12(9-10):377. | https://doi.org/10.15836/ccar2017.377

*ADDRESS FOR CORRESPONDENCE: Zvonimir Ostojić, Klinički bolnički centar Zagreb, Kišpatićeva 12, HR-10000 Zagreb, Croatia. / Phone: +385-91-895-0702 / E-mail: ostojiczvonimir@gmail.com

ORCID: Zvonimir Ostojić http://orcid.org/0000-0003-1762-9270 • Zoran Miovski http://orcid.org/0000-0002-3850-8905 Marija Brestovac http://orcid.org/0000-0003-1542-2890 • Joško Bulum http://orcid.org/0000-0002-1482-6503

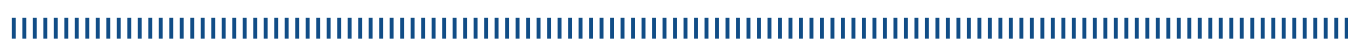

Introduction: Contrast induced nephropathy (CIN) following invasive cardiovascular interventions (ICI) is associated with increased mortality and morbidity ${ }^{1}$. Although, it occurs more frequently in high risk patients with renal failure (RF) and diabetes mellitus (DM), incidence up to $10 \%$ has been described in patients without $\mathrm{DM}^{2}$. Some research suggest that urgent contrast requiring procedures elevate CIN incidence in overall population. Aim of this study was to compare CIN incidence in non-DM patients after ICI depending on the urgency of procedure.

Patients and Methods: We retrospectively observed all patients undergoing ICI requiring contrast in 2015. From 2756 patients, we included 323 non-diabetic patients who had serum creatinine level (SCL) measured before ICI and at least one time between 24 and 72 hours following ICI. CIN was defined using grading system in two stages; 1 . SCL increase $\geq 25 \%$ and $<44 \mu \mathrm{mol} / \mathrm{L}$ above baseline and 2 . SCL rise $>44 \mu \mathrm{mol} / \mathrm{L}$ above baseline. Patients were stratified accordingly in 3 groups no-CIN, CIN-1 and CIN-2 Complexity of ICI was assessed using total procedure duration (PD), fluoroscopy time (FT) and contrast volume (CV).

Results: From total 323 patient (age 63.8 \pm 15.3 ) 101 (31.3\%) were female. Compared with men they were significantly older $(69.1 \pm 16.7$ vs $61.5 \pm 19.9, \mathrm{p}<0.001)$ and had worse RF (eGFR - $64.85 \pm 2.26$ vs $79.62 \pm 25.16$ $\mathrm{ml} / \mathrm{min} / 1.73 \mathrm{~m} 2, \mathrm{p}<0.001$ ). Elective procedure was done in $39.95 \%$. Average PD was $40.82 \pm 38.2 \mathrm{~min}$ with $10.8 \mathrm{~min}$ FT. During ICI $168.8 \pm 113.4 \mathrm{ml}$ of CV was used. Overall CIN incidence was $17.02 \%$ (N=55), from which $65.45 \%(\mathrm{~N}=36)$ was defined as stage 1 . Between urgent and elective procedure there was no significant difference in CIN incidence ( $p>0.6)$. Interestingly, elective patients had lower baseline eGFR (70.6 \pm 25.9 vs. $78.6 \pm 24.6, p=0.006)$. There was no significant difference in other previously mentioned observed parameters. After comparison of all data between groups, we found significant difference only in gender, with women having higher rate of CIN in all groups $(\mathrm{p}<0.05)$. Also, between no-CIN and CIN-1 vs to CIN-2 group we observed lower baseline eGFR in CIN-2 ( $p<0.05)$. The same diversity was observed within each gender.

Conclusion: Results of our study suggest high overall CIN incidence of $17 \%$, with no difference considering urgency of procedure. All these results must be taken with caution due to potential selection bias in elective group. In our opinion, results here described, represent smaller, more morbid percentage of total elective patients (only $6.62 \%$ of totally screened elective patients were included). This might happened because elective ICI are usually one day procedures. Also, observation that CIN is commoner in female gender is probably influenced by confounding factor; older age and worse renal function in women. Just as previously described, our results suggest that low eGFR is important risk factor for CIN development, just as lower eGFR in connected with more sever stage of CIN

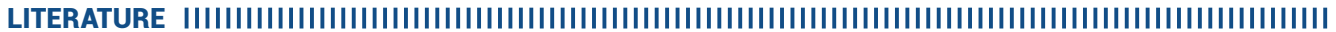

1. Giacoppo D, Madhavan MV, Baber U, Warren J, Bansilal S, Witzenbichler B, et al. Impact of Contrast-Induced Acute Kidney Injury After Percutaneous Coronary Intervention on Short- and Long-Term Outcomes: Pooled Analysis From the HORIZONS-AMI and ACUITY Trials. Circ CardiovasC Interv. 2015 Aug;8(8):e002475. https://doi.org/10.1161/CIRCINTERVENTIONS.114.002475

2. Santos PR, Carneiro Neto JD, Arcanjo FP, Carneiro JK, Carneiro RC, do Amaral CL. Contrast induced nephropathy after primary angioplasty for acute myocardial infarction. J Bras Nefrol. 2015 Oct-Dec;37(4):439-45. https://doi.org/10.5935/0101-2800.20150070 